\title{
Article
}

\section{Treatment of psychopathy: a conceptual and empirical review}

\author{
Lewis, Michael \\ Available at http://clok.uclan.ac.uk/23590/ \\ Lewis, Michael ORCID: 0000-0001-5567-3569 (2018) Treatment of \\ psychopathy: a conceptual and empirical review. Journal of Criminological \\ Research, Policy and Practice, 4 (3). pp. 186-198. ISSN 2056-3841
}

It is advisable to refer to the publisher's version if you intend to cite from the work. http://dx.doi.org/10.1108/JCRPP-06-2018-0019

For more information about UCLan's research in this area go to

http://www.uclan.ac.uk/researchgroups/ and search for <name of research Group>.

For information about Research generally at UCLan please go to http://www.uclan.ac.uk/research/

All outputs in CLoK are protected by Intellectual Property Rights law, including Copyright law. Copyright, IPR and Moral Rights for the works on this site are retained by the individual authors and/or other copyright owners. Terms and conditions for use of this material are defined in the policies page.

\section{CLoK}

Central Lancashire online Knowledge www.clok.uclan.ac.uk

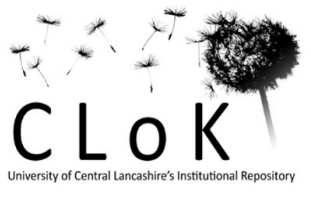




\section{Treatment of psychopathy: A conceptual and empirical} review

\begin{tabular}{|r|l|}
\hline Journal: & Journal of Criminological Research, Policy and Practice \\
\hline Manuscript ID & JCRPP-06-2018-0019.R1 \\
\hline Manuscript Type: & Review Paper \\
\hline Keywords: & $\begin{array}{l}\text { Psychopathy, Treatment, Cognitive remediation, Cognition, Affect, Schema, } \\
\text { Trauma }\end{array}$ \\
\hline \multicolumn{2}{|l}{} \\
\hline
\end{tabular}




\title{
Treatment of psychopathy: A conceptual and empirical review
}

\begin{abstract}
Purpose: For decades, psychopathy has been thought to be untreatable. Yet, conceptualisations, and indeed its assessment, have deviated away from viewing the disorder as personality pathology towards a behavioural focus where the core underlying deficits in cognition and affect have been ignored. Interventions have followed suit leading to a premature discounting of the role of therapy in adjusting psychopathic traits.

Design/methodology/approach: The review critically evaluates the conceptual and empirical evidence relevant to the treatment of psychopathy, deciphering components integral to the disorder that require intervention. Psychopathy is approached from a developmental perspective, with the review identifying several mechanisms thought to be responsible for precipitating and perpetuating its expression.

Findings: There appears some utility in targeting psychopathy from multiple angles, addressing experiences of trauma, associated schemas and the underlying cognitive-affective dysfunction noted to give rise to psychopathic traits. A new model for treatment was proposed integrating these factors in the hope that this will encourage the design of effective interventions that will address the origins and underlying deficits of the disorder, rather than symptomology.

Originality/value: The review encourages future research to consider the aetiology of psychopathy, with the aim of informing early intervention and containing the disorder whilst in its infancy, as well as addressing neurobiological dysfunction when most malleable.
\end{abstract}

Keywords: Psychopathy; treatment; cognitive remediation; cognition; affect; schema; trauma Article classification: General review. 


\section{Introduction}

Psychopathic individuals are a high-risk, high-need group (Simourd and Hoge, 2000), yet are commonly thought to be untreatable (Salekin, Worley and Grimes, 2010). These negative perceptions have become engrained in clinical practice, demonising the disorder and hampering theoretical and practical developments in its treatment. However there have been a number of recent, albeit tentative, indicators that treatment may in fact be successful (Polaschek and Daly, 2013). Substantial barriers to further progress remain, with confusion surrounding how psychopathy is measured and defined.

The review will begin by considering how psychopathy has been conceptualised and assessed, and the relevance this has to understanding, developing and evaluating treatment. It will then move on to explore the empirical investigation of psychopathy-related treatment, identifying potential reasons for prematurely discounting the role of therapy in adjusting psychopathic traits. Finally, a more recent technologically-orientated therapeutic approach will be discussed prior to outlining a new model of psychopathy treatment incorporating concepts highlighted as important throughout this review. It is hoped that this model can then be applied to advance understanding of the disorder's aetiology, thus allowing for more meaningful treatment design.

\section{Conceptualising psychopathy: What does this mean for treatment?}

Research has drawn attention to a unique subgroup of offenders diagnosed with psychopathy and characterised by a lack of psychiatric comorbidity (Blair, Mitchell and Blair, 2005), an inability to maintain interpersonal relationships (Conradi, Boertien, Cavus and Verschuere, 2016) and a resistance to change (Polaschek, 2010). Indeed, these are significant barriers that add nuance to a pessimistic outlook that such individuals are untreatable. Although this notion has a long standing history, it was Cleckley $(1941,1988)$ 
who explicitly noted that psychopaths are unlikely to benefit from psychological intervention, nor do they have the capacity to form an emotional attachment conducive to effective psychotherapy (de Ruiter, Chakhssi and Bernstein, 2016).

In his prototypical description of the disorder (also known as the primary psychopath; Karpman, 1948), Cleckley (1988) distinguished 'true' psychopathy (i.e. psychopathy as abnormal personality) from its antisocial variant (secondary psychopathy). He rejected claims that psychopathy stemmed from other psychiatric conditions, social anomalies or adverse early experiences, and instead, conceptualised the disorder as an expression of a genetic or biological predisposition where underlying affective deficits give rise to psychopathic functioning (Gullhaugen and Nǿttestad, 2012). An absence of emotion was considered to be at the centre of the disorder (Blair et al., 2005).

Hare (1970) conceptually refined and empirically validated this concept, operationalising Cleckley's early descriptions by developing the Psychopathy ChecklistRevised (PCL-R; Hare, 1991, 2003) to capture psychopathic traits in a reliable way. Though not without its criticism (See Lewis, in press), the PCL-R is held as the "gold standard" (Lynam and Gudonis, 2005, p. 383) for clinically assessing psychopathy, measuring the disorder through four highly correlated factors: 1). Interpersonal; 2). Affective; 3). Lifestyle; and 4). Antisocial (Hare, 2003).

This four-factor model has become synonymous with the current definition of psychopathy (Skeem and Cooke, 2010a), yet has been subject to scrutiny for incorporating antisocial aspects that were initially considered rare (e.g. Cleckley, 1988), and nothing more than behavioural manifestations of the fundamental intrinsic elements of the disorder (Cooke and Michie, 2001; Skeem and Cooke, 2010b). Driven by an over-focus on these behavioural characteristics, psychopathy has been viewed as 'criminal' as opposed to 'abnormal 
personality', and therefore considered predominantly as a forensic concern (Wilks-Riley and Ireland, 2012).

There has been some attempt, however, to revert conceptualisations of psychopathy back to abnormal personality. The Comprehensive Assessment of Psychopathic Personality (CAPP; Cooke, Hart, Logan and Michie, 2012), for instance, focuses on personality traits and their pathology rather than specific behaviours or characteristic adaptations (Flórez et al., 2018). The CAPP provides thorough coverage of the primary symptoms of psychopathy via a lexical framework where variations in personality are represented through normal language (Cooke et al., 2012). Symptoms within the CAPP are organised into six core domains capturing both functioning and developmental experiences (i.e. attachment, cognition, emotional, dominance, behavioural and self; Kreis, Cooke, Michie, Hoff and Logan, 2012). Understanding psychopathy through this broad hierarchical structure provides a promising foundation for treatment, where personality and its development appear to be key targets for intervention; yet these remain poorly integrated into the psychopathy literature due to the overlap with a behavioural entity.

Construing psychopathy as a behavioural syndrome presents a narrow and negative view of its characteristics, neglecting neutral and positive qualities (Blackburn, 2007), and inhibiting treatment efficacy. Understanding the more positive aspects of psychopathy, and indeed their development, will enable an optimism-based means of addressing difficulties (Seligman, 2006), thus allowing clients to focus on their strengths during psychological intervention (Wilks-Riley and Ireland, 2012). This is still to be implemented in the treatment of psychopathy.

The classification of psychopathy within the current Diagnostic and Statistical Manual of Mental Disorders (DSM-V; American Psychiatric Association [APA], 2013) adds additional complexity when attempting to conceptualise the disorder. It has not provided any 
means of specifically classifying or diagnosing psychopathy despite research attesting to the disorder's unique existence (Ogloff, Campbell and Shepherd, 2016; Widiger, 2006). Psychopathy as a standalone [categorical] diagnosis remains absent from DSM-V and has overlapped with the criteria for antisocial personality disorder (ASPD). Although there is empirical support for an asymmetric association between ASPD and psychopathy, with the majority of offenders meeting the diagnosis for ASPD but only a small proportion of these reaching the clinical threshold for psychopathy (Pham and Saloppe, 2010), the two disorders are in fact diagnostically different. ASPD is arguably a weak facsimile of psychopathy, lacking the core affective and interpersonal traits central to the condition (Strickland, Drislane, Lucy, Krueger and Patrick, 2013).

In contrast to earlier editions, DSM-V also proposed a dimensional trait-based approach to diagnosis, which falls within a comprehensive model of personality pathology (Morey, Skodol and Oldham, 2014). The trait-based model assumes that personality occurs along a continuum and captures psychopathy (or its antisocial variant) through the broad domains of antagonism, disinhibition and negative affect (APA, 2013). These domains have been compared against the Triarchic model of psychopathy, which delineates the disorder through three phenotypic constructs: disinhibition, boldness and meanness (Patrick, Fowles and Krueger, 2009). Indeed, there is overlap here with disinhibition and antagonism capturing much of the same "thematic terrain" as disinhibition and meanness from the Triarchic conceptualisation (Strickland et al., 2013, p. 328). It is boldness that appears to be key for differentiating psychopathy from ASPD (Berg, Lilienfeld and Sellbom, 2017), as the underlying elements of this domain (e.g. social efficacy, emotional stability and fearlessness) are not included in the trait-based model for DSM-V. The dimensional model, however, does hold merit for considering psychopathy as a heterogeneous rather than homogenous disorder 
(Husain, 1995) and therefore lends itself to an individualised-based treatment approach; one that considers individual personality traits as central to the expression of psychopathy.

It becomes apparent, nevertheless, that the clinical construct of psychopathy is not well represented in DSM-V. The criteria proposed is predominantly behavioural and the over reliance on criminality has raised concerns surrounding the lack of discriminative ability and diagnostic ubiquity among forensic samples (Marcus, Fulton and Edens, 2012; Miller and Lynam, 2012), as well as having a detrimental impact on treatment. Resultantly, there is a tendency to treat the behavioural expression of psychopathy rather than address its underlying cause or function. Reverting back to the original conceptualisation of the disorder and viewing psychopathy as abnormal personality (Cleckley, 1941) would go some way to resolving this.

Thus, research appears to have concentrated on the nature and consequences of psychopathic behaviour, neglecting the empirical investigation of factors that may assist more with treatment. For instance, the aetiology of psychopathy is poorly captured in the literature and understanding this may inform early intervention, as well as aiding the development of effective theoretically-derived psychological therapies specific to the disorder (Salekin, 2002). Indeed, attachment difficulties and adverse early experiences are considered contributory to the psychopath as 'psychologically damaged' (Blackburn, 2007). However what remains missing is a broad understanding of how psychopathic individuals perceive and interact with their surroundings following exposure to such challenges (Wilks-Riley and Ireland, 2012).

This moves us to examine cognition in psychopathy, which is empirically neglected in comparison to affect and behaviour (Lewis, 2014; Skeem and Cooke, 2010b). It has been described at a theoretical level, but remains absent from conceptualisations of the disorder (e.g. Hare, 2003). This also applies to treatment approaches, where Cognitive Behavioural 
Theory of Personality (Beck and Freeman, 1990) and Cognitive Analytic Theory of Personality Disorder (Young, Klosko and Weishaar, 2003) each incorporate dysfunctional cognition as a core element of personality, but do not extend this to the construct of psychopathy (Wilks-Riley and Ireland, 2012). Whilst both theories are readily applied to personality disorder (Hofmann, Asnaani, Vonk, Sawyer and Fang, 2012; Kahl, Winter and Schweiger, 2012), the absence of focus on psychopathy is surprising, as like personality disorder, psychopathy is a pathology based within destructive developmental experiences (Blackburn, 2007). The apparent absence of research on cognition and psychopathy undoubtedly stems from a failure to view psychopathy and personality disorder as separate entities. Whilst recognising that there is a degree of overlap, not acknowledging psychopathy as a distinct construct that exhibits different cognitive and affective deficits (Drislane, Vaidyanathan and Patrick, 2013) is arguably detrimental to treatment efficacy.

More recent discoveries in neurobiology have emphasised the importance of an intrinsic cognitive-affective mechanism underlying the disorder (Newman and BaskinSommers, 2011). There is substantial evidence that the core affective deficits considered central to primary psychopathy (e.g. a lack of empathy; Cleckley, 1941, 1988), are moderated by context, and indeed, cortical-subcortical brain interactions (Newman and BaskinSommers, 2011; Newman, Curtin, Bertsch and Baskin-Sommers, 2010). Dysfunction at the early stages of selection attention (also known as an 'early attention bottleneck') has been noted to interfere with the processing of information, including emotions (Baskin-Sommers, Curtin and Newman, 2011). This tendency to overlook important information, unless specifically relevant to goal-directed activity (Baskin-Sommers, Curtin and Newman, 2013; Glass and Newman, 2009), promotes inaccurate interpretations and unhelpful responding in psychopathy, as well as precipitating and perpetuating biases in other areas of cognition, such as schemas. 
Schemas are central to cognitive development; forming during childhood and integrate as the basic fundamental units of personality (Beck, 1967). Thus, they are expected to relate to psychopathy (Bernstein, Arntz and de Vos, 2007). Serving as an abstract plan and guide for interpreting information and problem solving (Young et al., 2003), schemas operate both inside (explicit) and outside of consciousness (implicit) attaching meaning to an event and influencing beliefs about oneself, others and the world (Beck, 1967; Beck and Freeman, 1990). They are susceptible to distortion, with adverse early experiences and temperament giving rise to maladaptive cognition making an individual vulnerable to psychopathology (Chakhssi, Bernstein and de Ruiter, 2014).

Early maladaptive schemas (EMS; Young et al., 2003), arising from developmental challenges, are chronic and deviant patterns of cognition and affect, which in combination with unhelpful coping responses, result in biased information processing and responding (Chakhssi et al., 2014). That is, externalizing behaviours, such as physical aggression and substance misuse, are essentially viewed as inappropriate coping responses to EMS. Although considered to be at the core of personality disorders (Bach, Simonsen, Christoffersen and Kriston, 2017; Young et al., 2003), EMS have rarely been applied to other personality disturbances, such as psychopathy.

One of the few studies (e.g. Chakhssi et al., 2014) addressing maladaptive cognition in psychopathy found the impulsive lifestyle and antisocial PCL-R facets to positively relate to EMS 'mistrust/abuse' and 'insufficient self-control', and negatively to EMS 'subjugation'. EMS demonstrated no association with the interpersonal or affective facets. Consistent with Cleckley's profile of the primary psychopath $(1941,1988)$, the authors concluded that the dysfunctional neural structures implicated in the affective impairment of psychopathy manifest as a consequence of genetics rather than maladaptive cognition. These findings convey the disorder to be multifaceted reflecting different underlying pathological 
mechanisms, including maladaptive cognition and neurobiological dysfunction, and accentuate the complexity when identifying specific treatment targets.

Wilks-Riley and Ireland (2012) broadened Young's description to include positive as well as negative cognitive schemas. Their findings confirmed cognition to be of equal significance across all psychopathy factors and deciphered a schema structure consisting of four main groupings: An 'others' schema (i.e. abusing/uncaring others) and three selfschemas (i.e. worthless/self-dislike, positive self and calm/happy). A clear role was identified for positive schema in psychopathy, with 'positive self' negatively predicting the disorder and 'calm/happy' manifesting as a positive predictor. Thus, the lack of association between psychopathy and EMS previously evidenced (e.g. Chakhssi et al., 2014) may instead represent an over focus on maladaptive cognition, neglecting positive beliefs and prematurely discounting a role for schema in the conceptualisation of the disorder.

Psychopathic traits do not appear to be predicted solely by negative characteristics. This has significant implications for intervention by indicating which schemas can be challenged (e.g. abusing/uncaring others and worthless/self-dislike), explored (e.g. calm/happy) and increased (e.g. positive self; Wilks-Riley and Ireland, 2012). The identification of individual core beliefs that extend beyond negative schemas to positive schemas facilitates an optimism-based approach to treatment, and also engenders a means for motivating clients and understanding protective factors (Seligman, 2006; Wingate et al., 2006).

Little is known about the aetiology of positive cognitive schemas in psychopathy; though anticipated to arise from 'healthy' developmental experiences. However, EMS, or negative schemas, are hypothesised to originate from hardship in childhood, such as abuse, neglect or abandonment (de Ruiter, Chakhssi and Bernstein, 2016). Research has linked childhood maltreatment to the disorder, with experiences of early relational trauma being 
conducive to higher levels of secondary psychopathy (e.g. Craparo, Schimmenti and Caretti, 2013; Kerig, Bennett, Thompson and Becker, 2012). Parental attachment and parenting styles have also been examined as potential precursors in the putative trajectory to psychopathy through the onset of callous-unemotional (CU) traits (e.g. Craig, Gray and Snowden, 2013; Hawes, Dadds, Frost and Hasking, 2011). Hawes et al. (2011), for example, noted that an increase in harsh and inconsistent parenting and decrease in positive involvement related to CU traits among children, thus providing preliminary support for the role of trauma in the development of psychopathy.

Betrayal trauma, or trauma perpetrated by a close other (Gobin and Freyd, 2014), has been linked to secondary psychopathy (i.e. the antisocial variant of 'true' psychopathy outlined by Cleckley; Karpman, 1948). Unlike individuals with primary psychopathy who present with an inherent lack of emotion, secondary psychopaths are proposed to engage in a process of dampening down their emotion to cope with traumatic experiences (Kerig et al., 2012; Porter, 1996). That is, their emotional detachment or numbness may act as an adaptive function that develops into an emotionally blunted interpersonal style contributing to antisocial behaviour and callousness towards others (Kerig et al., 2012; Orsillo, TheodoreOklata, Luterek and Plumb, 2007). This implies that in contrast to primary psychopathy, secondary psychopathy is acquired and therefore has significant implications for targeted interventions among children displaying psychopathic tendencies. However, further work is required to determine how psychopathic subtypes emerge in children and whether these variants differ as a result of parenting modifications. It is possible to conclude that individuals with secondary psychopathy would benefit from trauma-informed care (Dargis and Koenigs, 2017).

Thus, it becomes apparent that psychopathy is a multifaceted construct with complex developmental aetiology that has yet to be fully understood. Though initially captured as a 


\section{How effective is existing psychological treatment for psychopathy?}

Many deem the prognosis for psychopathy to be poor (Salekin et al., 2010; Skeem, Polaschek and Manchak, 2009). Research has cast strident conclusions that psychopathic individuals are resistant to various interventions (e.g. Morrissey, Mooney, Hogue, Lindsay and Taylor, 2007), demonstrate higher levels of attrition (e.g. Berger, Rotermund, Vieth and Hohnhorst, 2012), and obtain less therapeutic gain than their non-psychopathic counterparts (e.g. Chakhssi, de Ruiter and Bernstein, 2010; Harris and Rice, 2006). This therapeutic pessimism is pervasive and undermines motivation to search for, develop and refine effective 
treatment strategies (Salekin, 2002; Salekin et al., 2010). There has been little empirical investigation of the psychopathy-treatment relationship and even fewer attempts have been made to review psychopathic individuals post treatment. Thus, "clinical lore" (Salekin, 2002, p. 79) rather than reality appears to be driving the notion that psychopathy is an untreatable syndrome.

A meta-analytic review of 42 studies conducted by Salekin (2002) investigating a range of therapeutic approaches found cognitive-behavioural therapy (five studies; $\mathrm{N}=246$ ) to have a success rate of $62 \%$ in the treatment of psychopathy. Based on 17 studies $(\mathrm{N}=88)$, psychoanalytic therapy also proved effective with a success rate of 59\%. Combining cognitive-behavioural therapies with an insight-orientated approach (i.e. psychoanalysis) further increased success to $88 \%$, indicating that challenging unhelpful thoughts whilst increasing self-awareness may have some utility when treating the disorder.

Therapeutic communities (eight studies; $\mathrm{N}=372$ ), however, were identified as the least successful intervention with a success rate of $25 \%$ and this may reflect the lack of psychologist-client interaction required for ongoing motivation, support and direction (DeSorcy, Olver and Wormith, 2017; Hobson, Scott and Rubia, 2011). Closer scrutiny revealed that intensive individual therapy incorporating family members and input from others (e.g. fellow prisoners/patients) produced optimal results overall, thus relaying the importance of scope, intensity and duration in the adjustment of psychopathic traits.

Salekin's (2002) review sampled studies assessing various definitions of psychopathy: Cleckley's (19 studies), Hare's PCL-R (four studies) and others' (e.g. Craft, Partridge and unknown; 17 studies). Psychotherapy was identified as most effective for the Clecklyian conception. There are two conclusions that can be drawn from this; firstly, with an absence of serious and varied criminality, psychopathic individuals defined through Cleckley's criteria may be seen as more amenable to treatment and rated as such; and secondly, the lack of 
objective measures (e.g. the PCL-R) to assess for psychopathy and to evaluate change, may have led to an over reliance on opinion (Harris and Rice, 2006). Thus, there appears to be a need for more rigorous research designs when evaluating treatment. Perhaps, including a wide net of outcome variables will assist in monitoring change and address the divergent conceptions of psychopathy yet to reach a consensus.

More recent research adopting Hare's conceptualisation of psychopathy has evidenced less success in terms of treatment for adults (e.g. Olver and Wong, 2009; Olver, Lewis and Wong, 2013). More success, however, has been documented among adolescents with psychopathic traits (e.g. Caldwell, McCormick, Wolfe and Umstead, 2012). Basic personality traits at this age are argued to be less stable and therefore more amenable to change (Blonigen, 2010). Behaviours associated with such personality traits are also more susceptible to situational and social influences during adolescence (Caspi and Roberts, 2001), which further reinforces the benefits of early-intervention when treating psychopathy and its behavioural manifestation.

Moving on to examine the treatment of adults with psychopathic traits, Olver and Wong (2009) identified that psychopathic sex offenders $(\mathrm{N}=45)$, assessed via the PCL-R, were more likely to withdraw from treatment and violently recidivate compared to nonpsychopathic controls $(\mathrm{N}=111)$. However, once psychopathy was controlled for an improvement in recidivism was noted.

In a later study, Olver et al. (2013) explored therapeutic change and violent recidivism among 152 high-risk violent offenders; of which 98 met the 25-point PCL-R cutoff for diagnosis. Higher levels of psychopathy were associated with decreased therapeutic progress and risk reduction. However the authors proposed that having many $\mathrm{CU}$ traits did not undermine treatment, rather it was their translation into difficulties in developing therapeutic alliance, insight, accepting responsibility, challenging distorted thinking, and 
recognising harm inflicted on others that posed the problem. CU traits therefore appear to be a potent responsivity issue in psychopathy (Wong and Gordon, 2013) and becomes a target for intervention.

Representing the CU features of psychopathy, individuals with high affective PCL-R facet scores are likely to struggle when developing an emotional connection to their primary therapist (Olver and Wong, 2009). DeSorcy et al. (2017) found this to be the case among a sample of 111 offenders undertaking an adapted sex offender treatment programme. Those scoring high on the PCL-R affective facet were associated with weaker therapeutic bonds $(r=$ -.19). However this was not the case for all, with $85 \%$ of the men scoring 25 or higher on the PCL-R demonstrating the capacity to establish working alliances and complete the intervention. Developing a therapeutic alliance therefore becomes a protective mechanism conducive to a successful therapeutic outcome, which even high scoring men on the PCL-R can evidently achieve with support.

What becomes apparent, however, is the general lack of treatment developed specifically for psychopathy as a global construct and at facet-level. The focus on reducing criminal recidivism rather than tackling the underlying causes of psychopathy is a clear indication that the disorder is still being viewed as a behavioural entity, and consequently, deficits such as those relating to cognition and affect are going unnoticed. Even the more recent interventions for psychopathy (e.g. Chromis; Tew, Dixon, Harkins and Bennett, 2012) use aggression as a gauge for treatment efficacy. Though it is worth noting that Chromis does recognise the importance of cognitive schemas in psychopathy, which has positive implications for addressing the underlying core beliefs inherent to the disorder. Indeed, dismantling the construct and examining specific elements, such as the cognitive and affective deficits, will help decipher those features amenable to treatment from those that are 
particularly challenging (Salekin et al., 2010). It may be that treating one component has a cascading effect on others.

Nevertheless, there is little evidence that traditional psychological interventions are effective for psychopathy among adults and this strengthens the need for a rethink in terms of what works. Many of the psychopathy-related treatment studies have poor methodological designs, exacerbated by small sample sizes, inappropriate outcome measures, a lack of consideration for theory and differing definitions of the disorder (Harris and Rice, 2006). There is also a need to include follow-up cases upon completion of treatment, as well as matched control groups where psychopathy remains the similar observable characteristic (Reidy, Kearns and DeGue, 2013). These are ideally the most promising modes of examining therapeutic outcome, yet are not well implemented across existing interventions. Arguably, such limitations have resulted in researchers and clinicians prematurely discounting the benefits of treatment for those with psychopathy, which has stunted further empirical exploration in this area (Salekin et al., 2010). That said, it may be that current interventions for psychopathy fall short (Kemp and Baskin-Sommers, in press), failing to capture core underlying deficits, thus proving to be ineffective.

More recent theoretical understandings of psychopathy, such as those relating to the 'early attention bottleneck', have encouraged the development of innovative approaches that integrate basic research with clinical practice (Kemp and Baskin-Sommers, in press). There is some evidence, albeit premature, that these novel approaches may be effective in the adjustment of psychopathic traits and will be discussed next alongside suggestions for a new treatment model.

\section{Future directions and conclusion}


Technological advances in individualised treatment have begun to emerge that may have some utility in resolving the psychopathy-related cognitive-affective dysfunction. As noted, psychopathic individuals have a fundamental deficit when attending to contextual cues, which give rise to undesirable responding (Newman and Baskin-Sommers, 2011). Whilst located in several neural structures of the brain (e.g. the amygdala, orbito-frontal cortex and prefrontal cortex; Kemp and Baskin-Sommers, in press), the malleability of these dysfunctions have become a potential target for treatment.

Central to this is cognitive remediation, an intervention grounded in understanding the mechanisms of behaviour with a goal of improving functioning (Breitborde et al., 2017). It aims to enhance cognitive skills, such as sustained attention, to modify behaviour (Virk, Williams, Brunsdon, Suh and Morrow, 2015) and has demonstrated to be successful among disorders with similar cognitive abnormalities to psychopathy (e.g. attention deficithyperactivity disorder; O’connell, Bellgrove, Dockree and Robertson, 2006). Thus, there appears to be promise in tailoring cognitive remediation techniques to target specific cognitive-affective mechanisms underpinning the disorder.

Adopting a technological approach to treatment, Baskin-Sommers, Curtin and Newman (2015) designed a computerised-experimental training programme to address the attentional deficits associated with psychopathy among 124 adult male offenders classified as either psychopathic or non-psychopathic. Individuals were randomly assigned to one of two training packages, each addressing a particular difficulty. Whilst the experimental training addressed the psychopathy-related attention to context deficit (e.g. rule changes using a reversal learning task; See Baskin-Sommers et al., 2015), the control training focussed on general affect regulation and cognitive control; deficits not specific to psychopathy (Kemp and Baskin-Sommers, in press). 
Upon completion of the six weeks training, psychopathic participants in the experimental condition demonstrated significant improvement when attending to contextual cues. However, those in the control condition evidenced no improvement on the nonpsychopathy specific-tasks. These findings demonstrate the possible benefits for integrating cognitive remediation interventions with other therapeutic approaches (e.g. schema therapy) to tackle the cognitive-affective dysfunction associated with psychopathy and aid functioning (Baskin-Sommers et al., 2015). Targeting the disorder from multiple angles may have the greatest potential for addressing complex psychopathic traits regardless of whether they are acquired or congenital. It may be that traditional treatment approaches are ineffective on their own (Kemp and Baskin-Sommers, in press). This moves the review on to consider a new model for the treatment of psychopathy.

Adapted from the schema-based model outlined by de Ruiter et al. (2016, p. 397), figure one draws on the important concepts highlighted throughout this review and conveys them as specific individual treatment targets. The model captures the developmental origins of psychopathy (i.e. trauma/adverse early experiences and temperament), the factors maintaining the disorder (i.e. schema and coping response) and those that are central to the expression of traits (i.e. cognition, affect and behaviour). It assumes that early development results in subsequent dysfunction (Salekin and Lochman, 2008). That is, adverse early experiences, temperament and trauma foster the formation of negative cognitive schemas, which subsequently promote biased cognition and affect, and unhelpful behaviour. Indeed, positive cognitive schemas and protective factors may act as a buffer to psychopathy and these are to be incorporated more into treatment.

Figure one goes about here 
It would be unreasonable to suggest that psychopathy originates from a single influence (i.e. trauma/adverse early experiences) and manifests through a linear process (Salekin et al., 2010). However, the simplistic approach outlined here offers a foundation to begin investigation into effective interventions that will address the underlying deficits, rather than symptomology. It is hoped that theories of therapeutic change specific to psychopathy will be proposed as research on this topic unfolds. Such theories are required to understand the processes and procedures involved when adjusting psychopathic traits, or making them less impactful on society (Salekin et al., 2010).

The new model approaches the disorder from a developmental perspective, thus appearing to be specific to secondary psychopathy (i.e. psychopathy that is acquired rather than inherited; Karpman, 1948). However, the hereditary component of primary psychopathy (i.e. the neurobiological deficits giving rise to cognition-affective dysfunction) viewed as untreatable may be contained through cognitive remediation. The model therefore goes some way to address both psychopathy subtypes.

This review naturally concludes by relaying the requirement for further research on the aetiology of psychopathy to better understand the pathological mechanisms underpinning the disorder and refine its definition. Such awareness will allow for early identification and the administration of specific treatments, thus containing the disorder whilst in its infancy. Advances in treatment technology should also be pursued to address the psychopathy-related attention to context deficit and improve functioning among those who would normally be resistant to psychological intervention.

\section{References}

American Psychiatric Association. (2013), Diagnostic and statistical manual of mental disorders ( $5^{\text {th }}$ ed.), Author, Washington, DC. 
Anderson, N.E., and Kiehl, K.A. (2014), "Psychopathy: Developmental perspectives and their implications for treatment", Restorative Neurology and Neuroscience, Vol. 32 No. 1, pp. 103-117.

Bach, B., Simonsen, E., Christoffersen, P., and Kriston, L. (2017), "The Young Schema Questionnaire 3 Short Form (YSQ-S3): Psychometric properties and association with personality disorders in a Danish mixed sample”, European Journal of Psychological Assessment, Vol. 33 No. 2, pp. 134-143.

Baskin-Sommers, A.R., Curtin, J.J., and Newman, J.P. (2011), "Specifying the attentional selection that moderates the fearlessness of psychopathic offenders", Psychological Science, Vol. 22 No. 2, pp. 226-234.

Baskin-Sommers, A.R., Curtin, J.J., and Newman, J.P. (2013), "Emotion-modulated startle in psychopathy: Clarifying familiar effects”, Journal of Abnormal Psychology, Vol. 122 No. 2, pp. $458-468$.

Baskin-Sommers, A.R., Curtin, J.J., and Newman, J.P. (2015), “Altering the cognitiveaffective dysfunctions of psychopathic externalizing offender subtypes with cognitive remediation”, Clinical Psychological Science, Vol. 3 No. 1, pp. 45-57.

Beck, A.T. (1967), Depression: Cause and treatment, University of Pennsylvania Press, Pennsylvania, PA.

Beck, A.T., and Freeman, A. (1990), Cognitive therapy of personality disorders, Guildford Press, New York, NY.

Berg, J.M., Lilienfeld, S.O., and Sellbom, M. (2017), “The role of boldness in psychopathy: A study of academic and clinical perceptions", Personality Disorders: Theory, Research and Treatment, Vol. 8 No. 4, pp. 319-328. 
Berger, K., Rotermund, P., Vieth, E.R., and Hohnhorst, A. (2012), “The prognostic value of the PCL-R in relation to the SUD treatment ending", International Journal of Law and Psychiatry, Vol. 35 No. 3, pp. 198-201.

Bernstein, D.P., Arntz, A., and de Vos, M.E. (2007), "Schema-focused therapy in forensic settings: Theoretical model and recommendations for best clinical practice", International Journal of Forensic Mental Health, Vol. 6 No. 2, p. 169-183.

Blackburn, R. (2007), "Personality disorder and antisocial deviance: Comments on the debate on the structure of the Psychopathy Checklist - Revised", Journal of Personality Disorders, Vol. 21 No. 2, pp. 142-159.

Blair, J., Mitchell, D., and Blair, K. (2005), The psychopath: Emotion and the brain, Blackwell, Malden, MA.

Blonigen, D.M. (2010), "Explaining the relationship between age and crime: Contributions from the developmental literature on personality", Clinical Psychology Review, Vol. 30 No. 1, pp. 89-100.

Breitborde, N.J.K., Woolverton, C., Dawson, S.C., Bismark, A., Bell, E.K., Bathgate, C.J., and Norman, K. (2017), "Meta-cognitive skills training enhances computerized cognitive remediation outcomes among individuals with first-episode psychosis", Early Intervention in Psychiatry, Vol. 11 No. 3, pp. 244-249.

Caldwell, M.F., McCormick, D., Wolfe, J., and Umstead, D. (2012), “Treatment-related changes in psychopathy features and behaviour in adolescent offenders", Criminal Justice and Behavior, Vol. 39 No. 2, pp. 144-155.

Caspi, A., and Roberts, B.W. (2001), "Personality development across the life course: The argument for change and continuity", Psychological Inquiry, Vol. 12 No. 2, pp. 4966. 
Chakhssi, F., Bernstein, D., and de Ruiter, C. (2014), "Early maladaptive schemas in relation to facets of psychopathy and institutional violence in offenders with personality disorders", Legal and Criminological Psychology, Vol. 19 No. 2, pp. 356-372.

Chakhssi, F., de Ruiter, C., and Bernstein, D. (2010), "Change during forensic treatment in psychopathic versus nonpsychopathic offenders", Journal of Forensic Psychiatry and Psychology, Vol. 21 No. 5, pp. 660-682.

Cleckley, H.M. (1941), The mask of sanity, Mosby, St. Louis, MO.

Cleckley, H.M. (1988), The mask of sanity: An attempt to clarify some issues about the socalled psychopathic personality, Mosby, St. Louis, MO.

Conradi, H.J., Boertien, S.D., Cavus, H., and Verschuere, B. (2016), "Examining psychopathy from an attachment perspective: The role of fear of rejection and abandonment”, Journal of Forensic Psychiatry and Psychology, Vol. 27 No. 1, pp. 92-109.

Cooke, D.J., Hart, S.D., Logan, C., and Michie, C. (2012), "Explicating the construct of psychopathy: Development and validation of a conceptual model, the Comprehensive Assessment of Psychopathic Personality (CAPP)", International Journal of Forensic Mental Health, Vol. 11 No. 4, pp. 242-252.

Cooke, D.J., and Michie, C. (2001), "Refining the construct of psychopathy: Towards a hierarchical model”, Psychological Assessment, Vol. 13 No. 2, pp. 171-188.

Craig, R.L., Gray, N.S., and Snowden, R.J. (2013), "Recalled parental bonding, current attachment, and the triarchic conceptualization of psychopathy", Personality and Individual Differences, Vol. 55 No. 4, pp. 345-350.

Craparo, G., Schimmenti, A., and Vincenzo, C. (2013), “Traumatic experience in childhood and psychopathy: A study on a sample of violent offenders from Italy", European Journal of Psychotraumatology, Vol. 4 No. 1, pp. 1-6. 
Dargis, M., and Koenigs, M. (2017), “Two subtypes of psychopathic criminals differ in negative affect and history of childhood abuse", Psychological Trauma: Theory, Research, Practice and Policy, Online First Publication, pp. 1-8.

de Ruiter, C., Chakhssi, F., and Bernstein, D.P. (2016), "Treating the untreatable psychopath", in Gacono, C.B. (Ed.), The clinical and forensic assessment of psychopathy: A practitioner's guide ( $2^{\text {nd }}$ ed.), Routledge, New York, NY, pp. 388402.

DeSorcy, D.R., Olver, M.E., and Wormith, J.S. (2017), "Working alliance and psychopathy: Linkages to treatment outcome in a sample of treated sexual offenders", Journal of Interpersonal Violence, Online First Publication, pp. 1-22.

Drislane, L.E., Vaidyanathan, U., and Patrick, C.J. (2013), "Reduced cortical call to arms differentiates psychopathy from antisocial personality disorder", Psychological Medicine, Vol. 43 No. 4, pp. 825-825.

Flórez, G., Ferrer, V., García, L.S., Crespo, M.R., Pérez, M., Saíz, P.A., and Cooke, D.J. (2018), "Clinician ratings of the Comprehensive Assessment of Psychopathic Personality (CAPP) in a representative sample of Spanish prison inmates: New validity evidence", PLOS one, Vol 13 No. 3, pp. 1-17.

Glass, S.J., and Newman, J.P. (2009), "Emotion processing in the criminal psychopath: The role of attention and emotion-facilitated memory", Journal of Abnormal Psychology, Vol. 118 No. 1, pp. 229-234.

Gobin, R.L., and Freyd, J.J. (2014), "The impact of betrayal trauma on the tendency to trust", Psychological trauma: Theory, Research, Practice and Policy, Vol. 6 No. 5, pp. 505511. 
Gullhaugen, A.S., and Nǿttestad, J.A. (2012), “Testing theoretical models for future clinical practice in the treatment of psychopathy", Journal of Forensic Psychiatry and Psychology, Vol. 23 Nos. 5-6, pp. 635-653.

Hare, R.D. (1970), Psychopathy: Theory and research, Wiley, London.

Hare, R.D. (1991), Manual for the Hare Psychopathy Checklist - Revised, Multi-Health Systems, Toronto, ON.

Hare, R.D. (2003), Manual for the Revised Psychopathy Checklist (2 ${ }^{\text {nd }}$ ed.), Multi-Health Systems, Toronto, ON.

Harris, G.T., and Rice, M.E. (2006), "Treatment of psychopathy: A review of empirical findings", in Patrick, C.J. (Ed.), Handbook of psychopathy, Guildford Press, New York, NY, pp. 555-572.

Hawes, D.J., Dadds, M.R., Frost, A.D.J., and Hasking, P.A. (2011), "Do childhood callousunemotional traits drive change in parenting practices?", Journal of Clinical Child and Adolescent Psychiatry, Vol. 40 No. 4, pp. 507-518.

Hobson, C.W., Scott, S., and Rubia, K. (2011), "Investigation of cool and hot executive function in ODD/CD independently of ADHD”, Journal of Child Psychology and Psychiatry, Vol. 52 No. 10, pp. 1035-1043.

Hofmann, S.G., Asnaani, A., Vonk, I.J.J., Sawyer, A.T., and Fang, A. (2012), “The efficacy of cognitive behavioral therapy: A review of meta-analyses", Cognitive Therapy and Research, Vol. 36 No. 5, pp. 427-440.

Husain, O. (1995), "Is the Rorschach of psychopaths the same on both sides of the Atlantic?", Rorschachiana, Vol. 20 No. 1, pp. 134-147.

Kahl, K.G., Winter, L., and Schweiger, U. (2012), “The third wave of cognitive behavioural therapies: What is new and what is effective?", Current Opinion in Psychiatry, Vol. 25 No. 6, pp. 522-528. 
Karpman, B. (1948), "The myth of the psychopathic personality", American Journal of Psychiatry, Vol. 104 No. 9, pp. 523-534.

Kemp, E., and Baskin-Sommers, A.R. (in press), "Using an experimental therapeutics approach to target psychopathy", in Dimidjian, S. (Ed.), Evidence-based practice in action, Guildford Press, New York, NY.

Kerig, P.K., Bennett, D.C., Thompson, M., and Becker, S.P. (2012), "Nothing really matters: Emotional numbing as a link between trauma exposure and callousness in delinquent youth", Journal of Traumatic Stress, Vol. 25 No. 3, pp. 272-279.

Kreis, M.K., Cooke, D.J., Michie, C., Hoff, H.A., and Logan, C. (2012), "The Comprehensive Assessment of Psychopathic Personality (CAPP): Content validation using prototypical analysis", Journal of Personality Disorders, Vol. 26 No. 3, pp. 402-413.

Lewis, M. (in press), “Assessing for psychopathy using the Psychopathy Checklist”, in Ireland, J.L., Ireland, C.A., and Birch, P. (Eds.), Violent and sexual offenders: Assessment, treatment and management ( $2^{\text {nd }}$ ed.), Routledge, London.

Lewis, M. (2014), "Understanding the affective and cognitive components of psychopathy: Developing a new assessment", Unpublished Doctoral Dissertation, University of Central Lancashire, Preston.

Lynam, D.R., and Gudonis, L. (2005), “The development of psychopathy”, Annual Review of Clinical Psychopathy, Vol. 1 No. 1, pp. 381-407.

Marcus, D.K., Fulton, J.J., and Edens, J.F. (2012), “The two-factor model of psychopathic personality: Evidence from the Psychopathic Personality Inventory", Personality Disorders: Theory, Research and Treatment, Vol. 4 No. 1, pp. 67-76. 
Miller, J.D., and Lynam, D.R. (2012), “An examination of the Psychopathic Personality Inventory's nomological network: A meta-analytic review”, Personality Disorders: Theory, Research and Treatment, Vol. 3 No. 3, pp. 305-326.

Morey, L.C., Skodol, A.E., and Oldham, J.M. (2014), “Clinician judgments of clinical utility: A comparison of DSM-IV-TR personality disorders and the alternative model for DSM-5 personality disorders”, Journal of Abnormal Psychology, Vol. 123 No. 2, pp. 398-405.

Morrissey, C., Mooney, P., Hogue, T. E., Lindsay, W.R., and Taylor, J.L. (2007), "Predictive validity of the PCL-R for offenders with intellectual disability in a high security hospital: Treatment progress", Journal of Intellectual and Developmental Disability, Vol. 32 No. 2, pp. 125-133.

Newman, J.P., and Baskin-Sommers, A.R. (2011), "Early selective attention abnormalities in psychopathy: Implications for self-regulation”, in Posner, M.I. (Ed.), Cognitive neuroscience of attention, Guildford Press, New York, NY, pp. 421-220.

Newman, J.P., Curtin, J.J., Bertsch, J.D., and Baskin-Sommers, A.R. (2010), “Attention moderates the fearlessness of psychopathic offenders", Biological Psychiatry, Vol. 67 No. 1, pp. 66-70.

O’connell, R.G., Bellgrove, M.A., Dockree, P.M., and Robertson, I.H. (2006), “Cognitive remediation in ADHD: Effects of periodic non-contingent alerts on sustained attention to response", Neuropsychological Rehabilitation, Vol. 16 No. 2, pp. 653-665.

Ogloff, J.R.P., Campbell, R.E., and Shepherd, S.M. (2016), “Disentangling psychopathy from antisocial personality disorder: An Australian analysis", Journal of Forensic Psychology Practice, Vol. 16 No. 3, pp. 198-215.

Olver, M.E., Lewis, K., and Wong, S.C. (2013), "Risk reduction treatment of high-risk psychopathic offenders: The relationship of psychopathy and treatment change to 
violent recidivism", Personality Disorders: Theory, Research and Treatment, Vol. 4 No. 2, pp. 160-167.

Olver, M.E., and Wong, S.C. (2009), “Therapeutic responses of psychopathic sexual offenders: Treatment attrition, therapeutic change and long-term recidivism", Journal of Consulting and Clinical Psychology, Vol. 77 No. 2, pp. 328-336.

Orsillo, S.M., Theodore-Oklata, C., Luterek, J.A., and Plumb, J. (2007), “The development and psychometric evaluation of the Emotional Reactivity and Numbing Scale", Journal of Nervous and Mental Disease, Vol. 195 No. 10, p. 830-836.

Patrick, C.J., Fowles, D.C., and Krueger, R.F. (2009), “Triarchic conceptualization of psychopathy: Developmental origins of disinhibition, boldness and meanness", Development and Psychopathology, Vol. 21 No. 3, pp. 913-938.

Pham, T.H., and Saloppe, X. (2010), "PCL-R psychopathy and its relation to DSM axis I and II disorders in a sample of male forensic patients in a Belgian security hospital", International Journal of Forensic Mental Health, Vol. 9 No. 3, pp. 205-214.

Polaschek, D.L.L. (2010), “Treatment non-completion in high-risk violent offenders: Looking beyond criminal risk and criminogenic needs", Psychology, Crime and Law, Vol. 16 No. 6, pp. 525-540.

Polaschek, D.L.L., and Daly, T.E. (2013), "Treatment and psychopathy in forensic settings", Aggression and Violent Behavior, Vol. 18 No. 5, pp. 592-603.

Porter, S. (1996), "Without conscience or without active conscience? The etiology of psychopathy revisited", Aggression and Violent Behavior, Vol. 1 No. 2, pp. 179-189.

Reidy, D.E., Kearns, M.C., and DeGue, S. (2013), "Reducing psychopathic violence: A review of the treatment literature", Aggression and Violent Behavior, Vol. 18 No. 5, pp. 527-538. 
Salekin, R.T. (2002), "Psychopathy and therapeutic pessimism: Clinical lore or clinical reality?", Clinical Psychology Review, Vol. 22 No. 1, pp. 79-112.

Salekin, R.T., and Lochman, J.E. (2008), “Child and adolescent psychopathy: The search for protective factors", Criminal Justice and Behavior, Vol. 35 No. 2, pp. 159-172.

Salekin, R.T., Worley, C., and Grimes, R.D. (2010), “Treatment of psychopathy: A review and brief introduction to the mental model approach for psychopathy", Behavioural Sciences and the Law, Vol. 28 No. 2, pp. 235-266.

Seligman, M.E.P. (2006), Learned optimism, Nicholas Brealey, London.

Simourd, D.J., and Hoge, R. (2000), “Criminal psychopathy: A risk-need perspective”, Criminal Justice and Behavior, Vol. 27 No. 2, pp. 256-272.

Skeem, J.L., and Cooke, D.J. (2010a), “One measure does not a construct make: Directions toward reinvigorating psychopathy research - Reply to Hare and Neumann (2010)”, Psychological Assessment, Vol. 22 No. 2, pp. 455-459.

Skeem, J.L., and Cooke, D.J. (2010b), "Is criminal behavior a central component of psychopathy? Conceptual directions for resolving the debate", Psychological Assessment, Vol. 22 No. 2, pp. 433-435.

Skeem, J.L., Polaschek, D.L.L., and Manchak, S. (2009), “Appropriate treatment works, but how? Rehabilitating general, psychopathic, and high risk offenders", in Skeem, J.L., Douglas, K., and Lilienfeld, S. (Eds.), Psychological science in the courtroom: Controversies and consensus. Guildford Press, New York, NY, pp. 358-384.

Strickland, C.M., Drislane, L.E., Lucy, M., Krueger, R.F., and Patrick, C.J. (2013), “Characterizing psychopathy using DSM-5 personality traits", Assessment, Vol. 20 No. 3, pp. 327-338.

Tew, J., Dixon, L., Harkins, L., and Bennett, A. (2012), "Investigating changes in anger and aggression in offenders with high levels of psychopathic traits attending the Chromis 
violence reduction programme”, Criminal Behaviour and Mental Health, Vol. 22 No. 3, pp. 191-201.

Virk, S., Williams, T., Brunsdon, R., Suh, F., and Morrow, A. (2015), “Cognitive remediation of attention deficits following acquired brain injury: A systematic review and metaanalysis", Neurorehabilitation, Vol. 36 No. 3, pp. 367-377.

Widiger, T.A. (2006), "Psychopathy and DSM-IV psychopathology", in Patrick, C. (Ed.), Handbook of psychopathy, Guildford Press, New York, NY, pp. 156-171.

Wingate, L.R., Burns, A.B., Gordon, K.A., Perez, M., Walker, R.L., Williams, F.M., and Joiner, T.E. (2006), "Suicide and positive cognitions: Positive psychology applied to the understanding and treatment of suicidal behaviour", in Ellis, T. (Ed.), Cognition and suicide: Theory, research, and therapy, American Psychological Association, Washington, DC, pp. 261-283.

Wilks-Riley, F., and Ireland, J.L. (2012), “Cognition and psychopathy: Identifying negative and positive schemas in general and forensic samples", Journal of Forensic Psychiatry and Psychology, Vol. 23 No. 4, pp. 466-484.

Wong, S.C.P., and Gordon, A. (2013), “The violence reduction programme: A treatment programme for violence-prone forensic clients", Psychology, Crime and Law, Vol. 19 No. 5-6, pp. 461-475.

Young, J.E., Kosko, J.S., and Weishaar, M.E. (2003), Schema therapy: A practitioner's guide, Guildford Press, New York, NY 


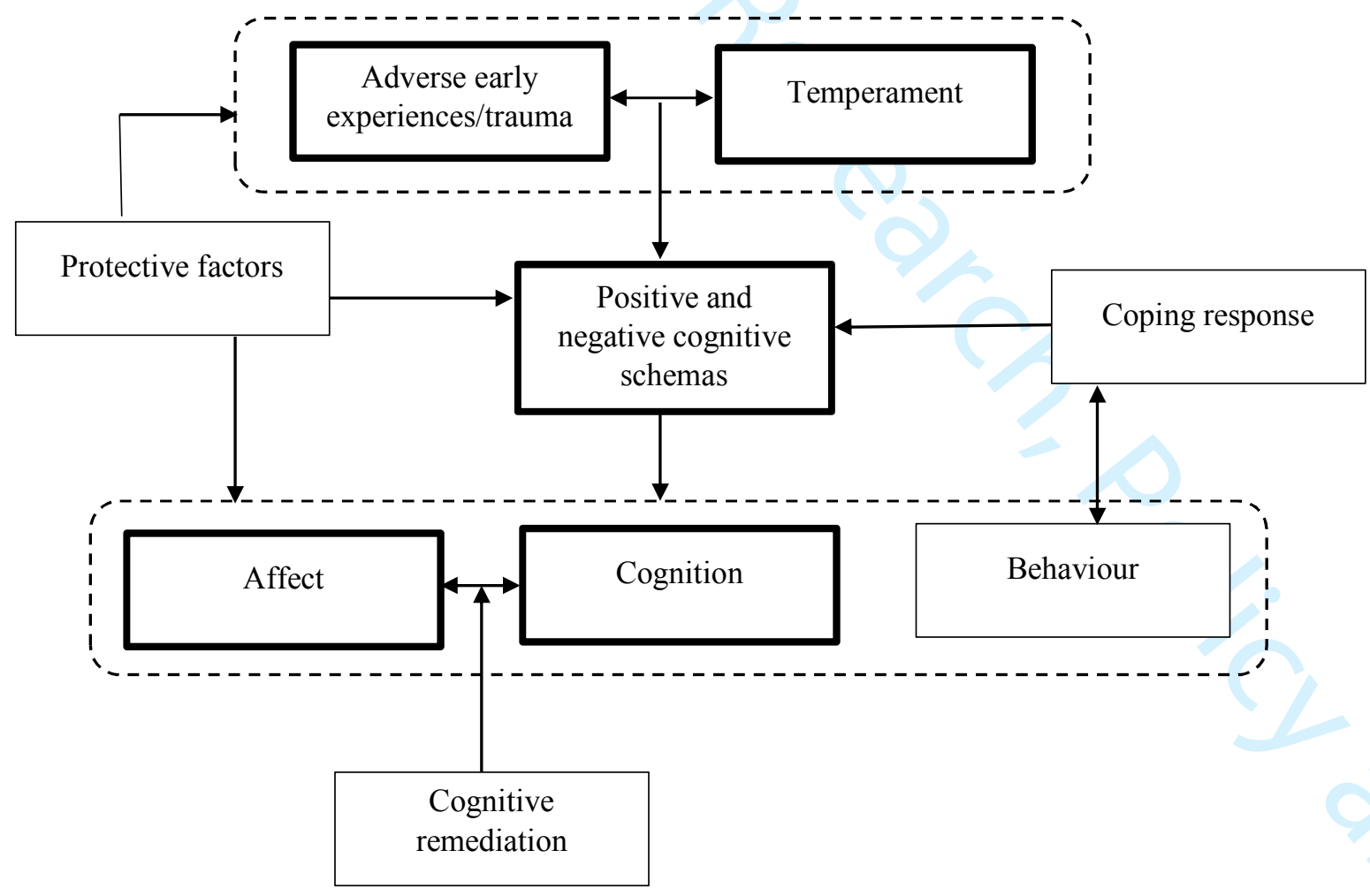

Figure 1: A new treatment model for psychopathy adapted from de Ruiter et al. (2016, p. 397). 